University of Massachusetts Amherst

ScholarWorks@UMass Amherst

Chemistry Department Faculty Publication Series

Chemistry

1998

\title{
Reduction of water loading effects in inductively coupled plasma mass spectrometry by a Nafion membrane dryer device
}

N Fitzgerald

JF Tyson

DA Leighty

Follow this and additional works at: https://scholarworks.umass.edu/chem_faculty_pubs

Part of the Chemistry Commons

\section{Recommended Citation}

Fitzgerald, N; Tyson, JF; and Leighty, DA, "Reduction of water loading effects in inductively coupled plasma mass spectrometry by a Nafion membrane dryer device" (1998). Journal of Analytical Atomic Spectrometry. 1067.

Retrieved from https://scholarworks.umass.edu/chem_faculty_pubs/1067 


\title{
Reduction of water loading effects in inductively coupled plasma mass spectrometry by a Nafion membrane dryer device
}

\author{
Neil Fitzgerald ${ }^{a}$, Julian F. Tyson ${ }^{* a}$ and David A. Leighty ${ }^{b}$ \\ ${ }^{a}$ Department of Chemistry, University of Massachusetts, Box 34510, Amherst, MA 01003-4510, USA \\ ${ }^{b}$ Perma Pure Inc., P.O. Box 2105, Toms River, NJ 08754-2105, USA
}

\begin{abstract}
A multi-strand $\mathrm{Nafion}^{\circledR}$ dryer, located between the spray chamber and torch of a plasma source mass spectrometer, removed about $97 \%$ of the total mass of water leaving the spray chamber. A significant reduction in the ratio of the oxide signal to that of the metal for cerium and barium was observed. The argon oxide and hydroxide signals at $\mathrm{m} / \mathrm{z}, 56$ and 57, respectively, were also decreased by about a factor of 10 for $m / z$ 56. In turn, an improvement in the detection limit for iron at this $m / z$ by about a factor of 5 was obtained. The use of the dryer did not require re-optimization of the instrument operating conditions and, for the relatively clean solutions introduced by flow injection used in this study, did not cause any significant memory effect or peak broadening.
\end{abstract}

Keywords: Inductively coupled plasma mass spectrometry; Nafion dryer; membrane desolvation; water loading; argon oxide; iron

Inductively coupled plasma source mass spectrometry (ICP-MS) is an extremely sensitive analytical technique whose performance is often critically affected by the sample introduction system. Aqueous samples are usually preferred due to their homogeneity and ease of handling; however, problems are encountered due to the solvent load in the plasma. Hutton and Eaton ${ }^{1}$ have shown that aerosol water can reduce the efficiency of the plasma for ion production and can produce interfering polyatomic and doubly charged species which are problematic for the determination of some elements. Attempts have been made to use desolvation systems to improve the sample introduction procedure by evaporating the solvent from the aerosol and removing the vapour produced by condensation. ${ }^{2,3}$ This condensation step has been found to reduce oxide and doubly charged species but is unable to eradicate water loading completely; in addition, it provides a mechanism for sample loss and memory effects by condensation of the solvent back onto the sample particles or loss of particles onto the cold surfaces. Alves et al. ${ }^{4}$ used a cryogenic desolvation system which allowed repetitive heating and cooling of an aerosol inside copper coils as a means of removing organic solvents.

Removal of solvent vapour via a membrane separator is an alternative to condensation and was first considered for atomic spectrometry by Gustavsson and co-workers, ${ }^{5,6}$ who used a silicone polymer membrane for the removal of organic solvents such as Freon and chloroform, achieving efficiencies of $80-100 \%$. The device was $\operatorname{modified}^{7,8}$ so that water vapour could be removed via 'a chemically modified ion exchange membrane' and it was shown, ${ }^{8}$ for a plasma source mass spectrometer, that the ratio of the signal due to uranium oxide to that due to uranium could be reduced. A porous PTFE membrane has also been used successfully for solvent reduction prior to introduction of a sample into a plasma. ${ }^{9,10}$ This system, while being chemically resistant and efficient for solvent reduction, is not specific for the solvent and may allow sample loss through the permeable membrane material. A non-porous polyimide membrane separator has been used as an alternative to porous membrane dryers. ${ }^{11}$ An aerosol produced by a cross-flow nebulizer and double pass spray chamber was passed through the polyimide dryer into an ICP-MS instrument. The high permeation rate for water vapour with this system led to much reduced oxide intensities, although problems were encountered due to buildup of electrostatic charge on the transfer tubing.

Nafion has many properties which make it suitable for use as a membrane separator for aqueous samples. It is a non-porous ion-exchange material which allows small polar molecules to pass through, while sample particles and non-polar molecules are unaffected. Its polymer backbone is similar to PTFE, making it very resistant to chemical attack. These properties have been successfully utilized by researchers for reducing water vapour in the determination of mercury, ${ }^{12}$ arsenic and selenium ${ }^{13}$ by chemical vapour generation atomic fluorescence spectrometry and for moisture removal in chemical vapour generation atomic absorption spectrometry. ${ }^{14}$ Recently, the use of a multi-strand Nafion dryer for aerosol desolvation during sample introduction in ICPAES has been investigated. ${ }^{15,16}$ An aerosol from a thermospray nebulizer was introduced into a heated spray chamber. The bulk of the solvent vapour was then removed with a Friedrichs condenser and the moisture content further decreased with a 200-strand Nafion dryer. The use of this system produced a significant improvement in detection limits for a number of elements compared with those for the thermospray system in the absence of the dryer and those obtained with conventional pneumatic nebulization sample introduction. Precision was also improved.

In this paper, we describe the results of an investigation of the ability of a Nafion dryer to reduce the water load in ICP-MS for a conventional nebulizer and spray chamber sample introduction system. The reduced water load leads to a decrease in the signal for oxide species and improvement in the detection limits for iron at $\mathrm{m} / \mathrm{z} 56$ and 57 which suffer from isobaric overlap from the ${ }^{40} \mathrm{Ar}^{16} \mathrm{O}^{+}$and ${ }^{40} \mathrm{Ar}^{16} \mathrm{O}^{1} \mathrm{H}^{+}$species, respectively.

\section{EXPERIMENTAL}

\section{Instrumentation}

A Perkin-Elmer SCIEX (Norwalk, CT, USA) Elan 5000 ICP-MS instrument was used with the operating conditions shown in Table 1. A conventional cross-flow nebulizer and double pass spray chamber were attached to the heated end of the dryer device while the other end was attached to the plasma torch via a PTFE connector and a length of PTFE tubing ( $280 \mathrm{~mm}$ long, $3.2 \mathrm{~mm}$ id, $6.4 \mathrm{~mm}$ od). The dryer system, shown schematically in Fig. 1, contained a Perma Pure (Toms River, NJ, USA) dryer consisting of 56 strands of Nafion (24 in long, 0.060 in id) in a stainless-steel cylinder inside a metal box, one side of which was heated to produce a longitudinal temperature gradient. The temperature of the exiting purge gas stream was displayed on an LED control panel on the exterior of the box which was also used to set the desired gas temperature. Flow injection experiments were conducted using 


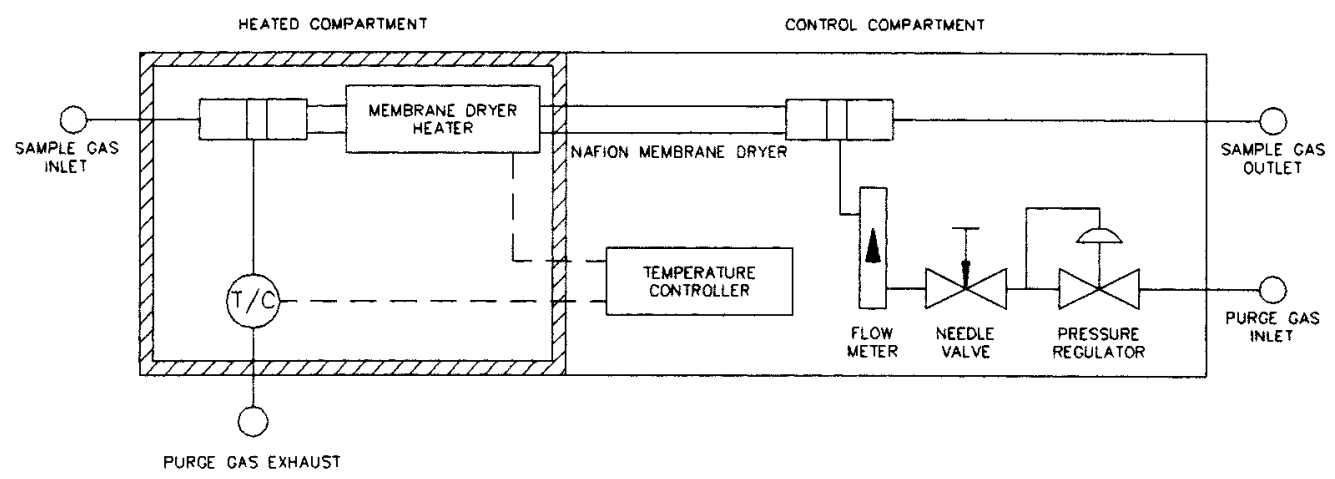

Fig. 1 Schematic diagram of dryer system.

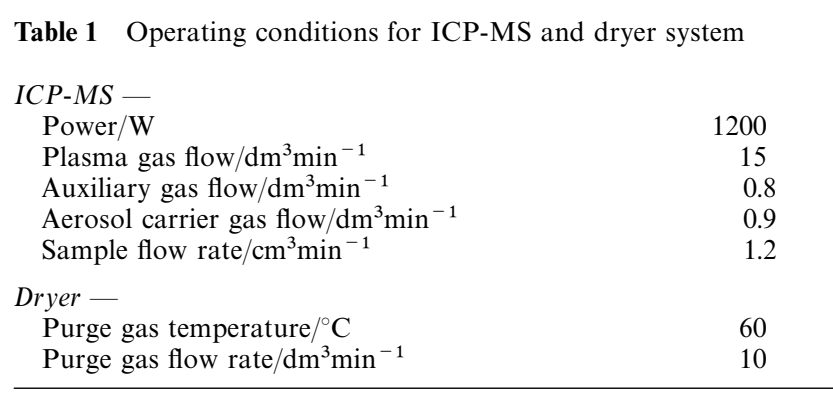

a Perkin-Elmer FIAS 200 unit with the program shown in Table 2. Sample was introduced through a $380 \mu$ sample loop. Data were exported into a text file from the Elan 5000 software and read into Microsoft Excel, where all further processing and graphing was performed.

\section{Reagents}

Iron standards were prepared by the dilution by mass of $1000 \mathrm{mg} \mathrm{dm}^{-3}$ ICP Fe standard solution (Johnson Matthey, Ward Hill, MA, USA) in 1\% nitric acid (sub-boiled analyticalreagent grade) with de-ionized water. A $10 \mathrm{mg} \mathrm{dm}^{-3}$ test solution was produced by a similar dilution in $1 \%$ acid of a $100 \mathrm{mg} \mathrm{dm}^{-3}$ test solution prepared from $1000 \mathrm{mg} \mathrm{dm}^{-3}$ barium, rhodium, magnesium, cerium and lead ICP standard solutions (Johnson Matthey).

\section{Optimization of plasma source mass spectrometer}

Instrument operating conditions of forward power, plasma gas flow, auxiliary gas flow, nebulizer gas flow and sample flow were optimized by a univariate method for the dryer system and for a normal spray chamber sample introduction system in order to achieve low $\mathrm{Ce}^{+} / \mathrm{CeO}^{+}, \mathrm{Ba}^{+} / \mathrm{BaO}^{+}$, and $\mathrm{Ba}^{2+} / \mathrm{Ba}^{+}$ratios and $\mathrm{ArO}^{+}$intensity for the test solution. Optimized conditions for the conventional sample introduction system were found to be very similar to the conditions for the dryer system (Table 1), indicating that the use of the dryer does not require extensive re-optimization of the ICP-MS operating conditions.

\section{Optimization and evaluation of dryer performance}

Initial experiments were performed with a 200-strand dryer; however, the bulk of the work was performed with the 56-strand device. The nature of the purge gas, purge gas flow rate and exiting purge gas temperature were optimized for a $10 \mathrm{mg} \mathrm{dm}^{-3}$ test solution for low $\mathrm{Ce}^{+} / \mathrm{CeO}^{+}, \mathrm{Ba}^{+} / \mathrm{BaO}^{+}$, and $\mathrm{Ba}^{2+} / \mathrm{Ba}^{+}$ratios and $\mathrm{ArO}^{+}$intensity. Dry nitrogen rather than air was used as the purge gas in order to eliminate the possibility of oxygen passing into the sample stream at higher dryer temperatures. The dryer system was also run with the sample uptake to the nebulizer closed in order to find the background intensity for $\mathrm{ArO}^{+}$. The ability of the dryer to remove water at various temperatures was studied with the system disconnected from the plasma torch. Weighed Drierite tubes (Fisher, Pittsburgh, PA, USA) were attached to the sample stream and the purge stream exits. An aerosol of de-ionized water was introduced into the system at $1.2 \mathrm{~cm}^{3}$ $\min ^{-1}$ with $0.95 \mathrm{dm}^{3} \mathrm{~min}^{-1}$ of argon as the nebulizer gas. The increases in mass of the tubes after about $20 \mathrm{~min}$ was assumed to be due to the total mass of water introduced, and the efficiency of transfer across the membrane was then calculated. In order to demonstrate the advantages of reduced water loading in ICP-MS determinations, the detection limits for the isotopes ${ }^{56} \mathrm{Fe}$ and ${ }^{57} \mathrm{Fe}$ were measured for the dryer sample introduction system and compared with those for conventional sample introduction under optimized conditions. Straight line calibration graphs were obtained for the data from flow injection introduction of 10,20 and $50 \mu \mathrm{g} \mathrm{dm}^{-3}$ standards in $1 \%$ nitric acid with an FIAS unit using the program shown in Table 2. Data points were collected with a dwell time of $50 \mathrm{~ms}$. The detection limits were calculated from the data for the flow injection peaks for $10 \mu \mathrm{g} \mathrm{dm}{ }^{-3}$ standards. The first 50 data points in each experiment were taken to be the background signal and the detection limit was calculated as three times the standard deviation of the background divided by the sensitivity based on peak height.

\section{RESULTS AND DISCUSSION}

With the 200-strand dryer, the back-pressure was too high to allow normal transport through to the plasma. Increasing the gas pressure caused aerosol to be forced out of the spray

Table 2 FIAS program for iron determination

\begin{tabular}{ccccc} 
& Time/s & $\begin{array}{c}\text { Pump 1 } \\
\text { speed/rev } \text { min }^{-1}\end{array}$ & $\begin{array}{c}\text { Pump 2 } \\
\text { speed/rev min }\end{array}$ & Valve position \\
Pre-sample & & 120 & 0 & Load \\
1 & 20 & 50 & 80 & Load \\
2 & 15 & 0 & 80 & Inject (read) \\
Post-run & 30 & 40 & 40 & Load \\
\hline
\end{tabular}


Table 3 Efficiency of the dryer system for water removal

\begin{tabular}{|c|c|c|c|c|}
\hline $\begin{array}{l}\text { Temperature/ } \\
{ }^{\circ} \mathrm{C}\end{array}$ & $\begin{array}{l}\text { Mass of water } \\
\text { collected from } \\
\text { sample gas } / \mathrm{g}\end{array}$ & $\begin{array}{l}\text { Mass of water } \\
\text { collected from } \\
\text { purge gas/g }\end{array}$ & $\begin{array}{c}\text { Total mass of } \\
\text { water } \\
\text { collected } / \mathrm{g}\end{array}$ & $\begin{array}{c}\text { Amount of } \\
\text { water removed } \\
\text { by dryer }(\%)^{*}\end{array}$ \\
\hline $\begin{array}{l}25 \\
45\end{array}$ & $\begin{array}{l}0.026 \\
0.021\end{array}$ & $\begin{array}{l}0.652 \\
0.514\end{array}$ & $\begin{array}{l}0.678 \\
0.535\end{array}$ & $\begin{array}{l}96 \pm 1 \\
96 \pm 1\end{array}$ \\
\hline 58 & 0.020 & 0.560 & 0.580 & $97 \pm 1$ \\
\hline 80 & 0.033 & 0.541 & 0.574 & $94 \pm 1$ \\
\hline 87 & 0.026 & 0.515 & 0.541 & $95 \pm 1$ \\
\hline 98 & 0.040 & 0.582 & 0.622 & $94 \pm 1$ \\
\hline
\end{tabular}

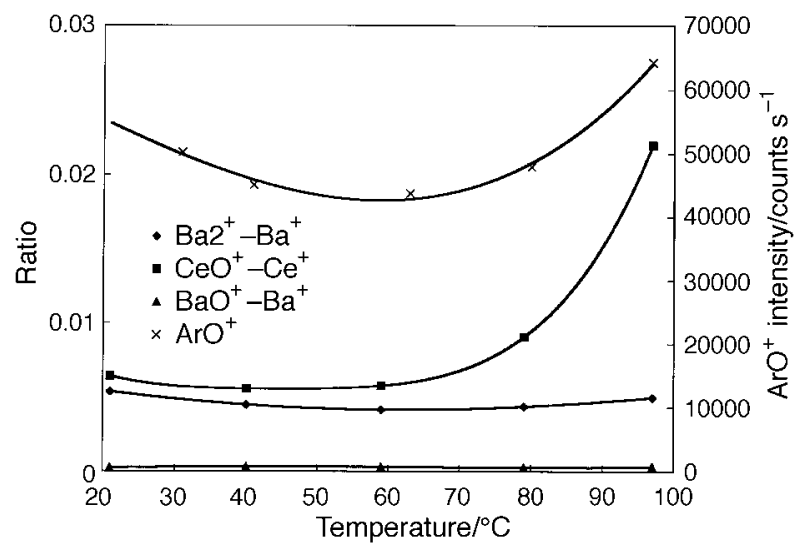

Fig. 2 Effect of dryer temperature on oxide ratios and argon oxide intensity.

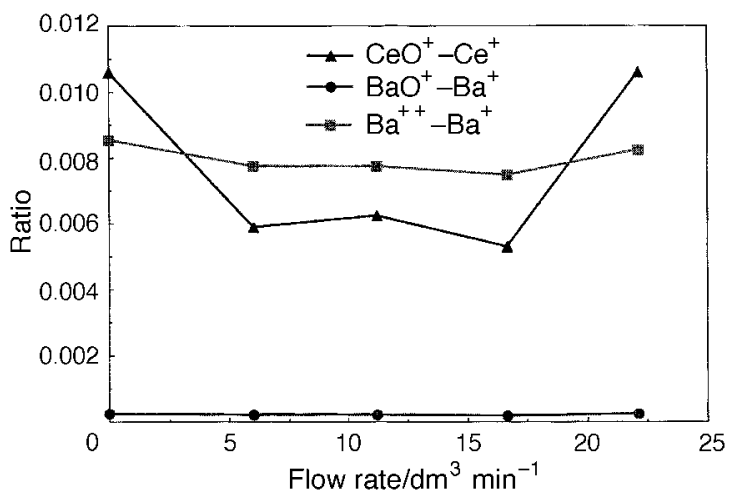

Fig. 3 Effect of purge gas flow rate on oxide ratios.

chamber via the drain tube. Rather than attempt to redesign the drainage system, subsequent experiments were performed with the 56-strand dryer, for which the back-pressure did not affect the normal flow of aerosol to the plasma. The performance of a Nafion dryer is a function of temperature and flow rate. However, as the flow rate has a crucial impact on the performance of the plasma source mass spectrometer, this parameter was kept fixed at the optimum for the spectrometer performance $\left(0.9 \mathrm{dm}^{3} \mathrm{~min}^{-1}\right)$. The temperature should be as low as possible without condensing (or freezing) the water

Table 4 Comparison of oxide ratios and $\mathrm{ArO}^{+}$intensities for conventional sample introduction and the dryer system

Conventional sample introduction

$\begin{array}{lcc}\mathrm{CeO}^{+} / \mathrm{Ce}^{+} & 1.58 \times 10^{-2} & 2.08 \times 10^{-3} \\ \mathrm{BaO}^{+} / \mathrm{Ba}^{+} & 1.59 \times 10^{-3} & 5.78 \times 10^{-4} \\ \mathrm{ArO}^{+} / \text {counts s}^{-1} & 90000 & 10000\end{array}$

Table 5 Detection limits for iron-56 and iron-57

\begin{tabular}{ccc} 
& $\begin{array}{c}\text { Detection limit } \\
\text { without dryer } / \mu \mathrm{g} \mathrm{dm}^{-3}\end{array}$ & $\begin{array}{c}\text { Detection limit with } \\
\text { dryer } / \mu \mathrm{g} \mathrm{dm}^{-3}\end{array}$ \\
${ }^{56} \mathrm{Fe}$ & 1.8 & 0.37 \\
${ }^{57} \mathrm{Fe}$ & 1.4 & 0.93 \\
\hline
\end{tabular}

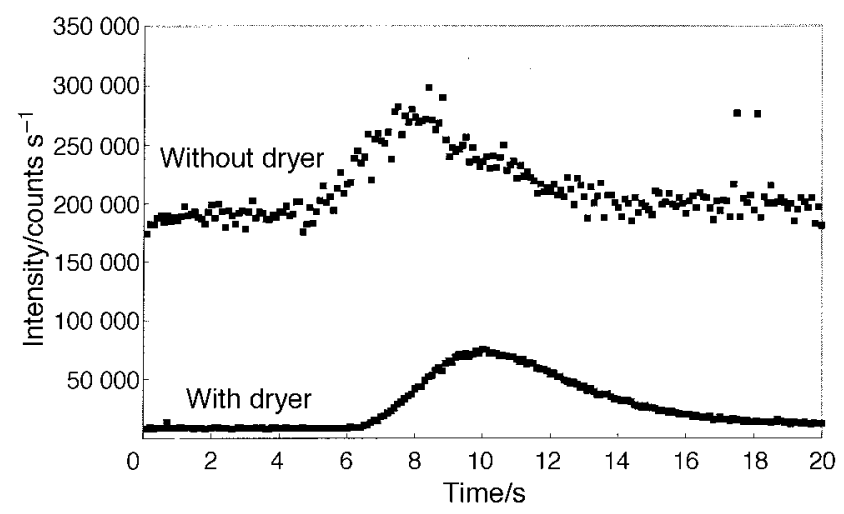

Fig. 4 Flow injection peak for a $10 \mu \mathrm{g} \mathrm{dm}{ }^{-3}$ iron solution in the absence and presence of the dryer.

vapour and so to remove large amounts of water, a temperature gradient is required.

\section{Effect of exiting purge gas temperature on dryer performance}

The results for the effect of exiting purge gas temperature on oxide ratios (shown in Fig. 2) indicated that an optimum temperature of about $60^{\circ} \mathrm{C}$ produced the lowest ratios for both cerium and barium and $\mathrm{ArO}^{+}$intensity. It is concluded that for the flow rate used in these studies, the temperature gradient which results in the greatest removal of water is that for which the exit temperature of the purge gas is about $60^{\circ} \mathrm{C}$. Similar results were obtained for the nitrogen and air purge gases, indicating that the effect of purge gas on the oxide ratios was negligible and that air was not leaking from the purge flow into the sample flow. Nitrogen was used as the purge gas in all subsequent experiments. The effect of exiting purge gas temperature on $\mathrm{ArO}^{+}$intensity also showed a minimum at around $60^{\circ} \mathrm{C}$.

\section{Effect of purge gas flow rate on dryer performance}

The effect of purge gas flow rate on oxide ratios is shown in Fig. 3 and indicates little effect for $\mathrm{BaO}^{+} / \mathrm{Ba}^{+}$and $\mathrm{Ba}^{2+} / \mathrm{Ba}^{+}$ ratios while the $\mathrm{CeO}^{+} / \mathrm{Ce}^{+}$ratio shows a minimum between 5 and $15 \mathrm{dm}^{3} \mathrm{~min}^{-1}$. The intensity of $\mathrm{ArO}^{+}$showed little or no dependence on the purge gas flow rate. A flow rate of $10 \mathrm{dm}^{3} \min ^{-1}$ was selected for all further experiments. 


\section{Efficiency of the dryer device for water removal}

The efficiency of the dryer as a function of purge gas temperature based on the mass increase of Drierite tubes is shown in Table 3. Replicate $(n=5)$ determinations of the efficiency at $58{ }^{\circ} \mathrm{C}$ were made, from which a $95 \%$ confidence interval of $\pm 1 \%$ was calculated. This indicates that there is a significant variation of efficiency with temperature above $60^{\circ} \mathrm{C}$ such that above this value, the efficiency decreases from its maximum value. This trend correlates with the variations of oxide intensities as a function of temperature (see Fig. 2). The maximum efficiency of the system was $97 \pm 1 \%$. It is thought that the rate at which vapour is transferred across the membrane increases with increasing temperature, but that the equilibrium water vapour partial pressure is higher at higher temperatures. Hence, in order to obtain the best drying effect, there should be a longitudinal temperature gradient. As water is introduced as both vapour and droplets and, as no quantitative information is available regarding the magnitude of the relevant rate and equilibrium constants for the dryer operation, selecting the optimum temperature will be based on experimental results. It is likely that the removal of water is a complex function of temperature, solvent loading and gas flows.

\section{Comparison with conventional sample introduction}

Comparisons of oxide ratios and intensities for conventional sample introduction with those obtained with the dryer device are shown in Table 4 for the optimized conditions in Table 1. The background intensity obtained when the sample uptake to the nebulizer was closed was found to be around 10000 counts $\mathrm{s}^{-1}$ and is thought to be due to the presence of oxideforming gases in the plasma arising from the surrounding atmosphere or from the argon gas supply. It is evident from these results that the dryer system is removing a large proportion of the water from the sample aerosol. The signal intensities of the test elements for the conventional sample introduction system and the dryer system were found to be similar, indicating little or no sample loss in the dryer. It should be noted that, for a sample introduction rate of 1.2 $\mathrm{cm}^{3} \mathrm{~min}^{-1}$ at a nebulization efficiency of $1 \%$ with removal of $97 \%$ of the water, the rate of oxygen introduction is still about $2 \times 10^{17}$ atoms s $^{-1}$.

\section{Detection limit for iron}

Flow injection peaks for ${ }^{56} \mathrm{Fe}$ in the absence and presence of the dryer are shown in Fig. 4. The reduction in water loading with the dryer present leads to a reduction in $\mathrm{ArO}^{+}$and $\mathrm{ArOH}^{+}$intensities at $m / z$ ratios of 56 and 57, respectively, such that the background intensities are significantly reduced. This reduction in background intensity leads to a reduction in the standard deviation of the background and, therefore, a reduction in the detection limits as shown in Table 5. It can also be seen from the relative widths of the flow injection peaks that the addition of the dryer system has little effect on the dispersion processes of aerosol transport and thus could be used in conjunction with liquid chromatography sample introduction with little contribution to peak broadening.

The provision and maintenance of the Elan 5000 ICP-MS and FIAS 200 instruments by Perkin-Elmer are gratefully acknowledged. Financial support from the CEM Corporation is gratefully acknowledged.

\section{REFERENCES}

1 Hutton, R. C., and Eaton, A. N., J. Anal. At. Spectrom., 1987, 2, 595

2 Tsukahara, R., and Kubota, M., Spectrochim. Acta, Part B, 1990, 45, 581 .

3 Hill, S. J., Hartley, J., and Ebdon, L., J. Anal. At. Spectrom., 1992, 7, 23.

4 Alves, L. C., Minnich, M. G., Wiederin, D. R., and Houk, R. S., J. Anal. At. Spectrom., 1994, 9, 399.

5 Gustavsson, A., Spectrochim. Acta, Part B, 1988, 43, 917.

6 Backstrom, K., Gustavsson, A., and Hietala, P., Spectrochim. Acta, Part B, 1989, 44, 1041.

7 Gustavsson, A., and Hietala, P., Spectrochim. Acta, Part B, 1990, 45, 1103.

8 McLaren, J. W., Lam, J. W., and Gustavsson, A., Spectrochim. Acta, Part B, 1990, 45, 1091.

9 Botto, R. I., and Zhu, J. J., J. Anal. At. Spectrom., 1994, 9, 905.

10 Brenner, I. B., Zhu, J., and Zander, A., Fresenius' J. Anal. Chem., 1996, 335, 774.

11 Tao, H., and Miyazaki, A., J. Anal. At. Spectrom., 1995, 10, 1.

12 Corns, W. T., Ebdon, L., Hill, S. J., and Stockwell, P. B., Analyst, 1992, 117, 717.

13 Corns, W. T., Stockwell, P. B., Ebdon, L., and Hill, S. J., J. Anal. At. Spectrom., 1993, 8, 71

14 Sundin, N. G., Tyson, J. F., Hanna, C. P., and McIntosh, S. A., Spectrochim. Acta, Part B, 1995, 50, 369.

15 Yang, J., Conver, T. S., Koropchak, J. A., and Leighty, D. A., Spectrochim. Acta, Part B, 1996, 51, 1491.

16 Conver, T. S., Yang, J., Koropchak, J. A., Shkolnik, G., and Flajnik-Rivera, C., Appl. Spectrosc., 1997, 51, 68.

Paper $7 / 03491 \mathrm{~A}$

Received May 20, 1997

Accepted October 8, 1997 